\title{
CONDIÇÕES DE TRABALHO DE PARTEIRAS TRADICIONAIS: ALGUMAS CARACTERÍSTICAS NO CONTEXTO DOMICILIAR RURAL
}

\author{
WORKING CONDITIONS OF TRADITIONAL BIRTH ATTENDANTS: \\ SOME CHARACTERISTICS AT HOME AND RURAL CONTEXT
}

BESSA. L.F. Condị̧ões de trabalho de parteiras tradicionais: algumas características no contexto domiciliar rural. Rev.Esc.Enf.USP, v.33, n.3, p.250.4, set. 1999.

\section{RESUMO}

Este é um estudo de abordagem qualitativa e dialética, que tem como objetivo analisar as condições de trabalho da parteira tradicional, numa perspectiva de trabalho reprodutivo e, portanto, desvalorizado economicamente. A análise foi construida tendo como categoria central o trabalho à partir de pressupostos marxista e feminista. Os resultados obtidos nos permitem afirmar que as parteiras realizam sen trabalho em precarias condiçose materiais, financeiras, relativas ao transporte e ao acesso e, ainda, ao ambiente de trabalho. A análise dessa prática nos proporcionou apresentar uma discussão em torno de algumas caracteristicas do trabalho da parteira tradicional, o qual se caracteriza como trabalho reprodutivo, desvalorizado economicamente, informal, autónomo e eminentemente feminino. S' configura, ainda. como uma prática social de saúde popular legitimada pela comunidade. Na prática obstétrica domiciliar rural evidenciamos relaçōes desiguais, à medida que homens e mulheres realizam atividades diferentes numa mesma ocupação, cabendo às mulheres as tarefas que reproduzem o papel feminino.

UNITERMOS: Parteira leiga. Trabalho feminino. Condições de trabalho.

\begin{abstract}
This is a study of qualitative and dialectical approach, which subject is to analize the working conditions of the traditional birth attendants, in a reproduclive perspective of work, and for this reason, economically undervalued. The analysis has been constructed having as central category the work, under marxist and feminist premises. Obtained results permit us to state these traditional birth a!lendants do their work in material and financial poor conditions, related to transportation, access, and still, working enviroment. The analysis of this practice has given us a possibility to present a discussion on some traits of the traditional birlh attendant's work, which is characterized as a reproductive work, economically undervalued, autonomous and eminently feminine. It still configures as a social practice of popular health, legitimated by the community. In the rural domestic obstetrics practice, unequal relations were in evidence since men and women play different roles in the same occupation. being women's responsability the reproduction of the feminine role.
\end{abstract}

UNITERMS: Midwaves. Practical. Women working. Working conditions.

\section{INTRODUÇÃO}

O interesse por investigar as condições de trabalho das parteiras tradicionais ocorreu em decorrência de uma antiga inquietude, relacionada com as políticas de saúde que não privilegiam a população rural, principalmente, no campo da saúde reprodutiva. Essa escolha fortaleceu-se pela nossa vinculação ao GEM- Grupo de Estudos sobre Saúde da Mulher -UFBA e pela prática profissional enquanto enfermeira e professora da área de saúde da mulher.

Por outro lado, entendemos que a definição de um problema de pesçuisa tem relação com a história de vidla e identidade da pesquisadora e orientadora, com o contexto histórico e social em que vivem.

\footnotetext{
- Professora Assistente do Departamento de Ciencias da Saúde da UFAC - Universidade Federal do Acre. Mestre ent Enfermagem pela UFBA.
} 
Sendo assim. procuramos na pesquisa, respostas para nossas indagações.

A partir desse olhar, penetramos na intimidade do trabalho das parteiras, ativiclade que acompanha a história da própria humanidade e, particularmente, a história da mulher. Por muitos milênios foi considerada uma prática eminentemente feminina, tradicionalmente realizada pelas mulheres, e somente a partir do século XIX. com a criação dlas escolas de medicina no Brasil, essa prática foi incorporada pelos médicos.

As falhas no sistema de saúle e as desigualdades sociais e regionais presentes principalmente nas zonas rurais. possibilitam, ainda no século presente, a atuação das parteiras.

Embora a assistencia institucional ao parto se constitua num direito já assegurado. boa parte das mulheres não tem acesso real a esse benefício. Senclo assim, a comunidade rural, vivendo em condições de total isolamento. utiliza o trabalho cla parteira não apenas para resolver problemas de saúde, mas também. como alternativa para resolver alguns dos problemas sócio-econômicos.

Por outro lado, a mulher parteira, como dona de casa e como trabalhadora, passa pela dificuldade de conciliar as responsabilidades domésticas no lar o fora dele já que tanto no munclo privado da família como no munclo trabalho, ela assume as tarefas domésticas e as relacionadas com o cuidado.

Considerando toda a problemática que envolve o trabalho da parteira, decidimos realizar a presente pesquisa, procurando identificar, no contexto rural, as condiçoes de trabalho das parteiras o as caracteristicas deste.

Partimos da hipotese de que o trabalho da parteira possui características semolhantes ao trabalho doméstico e apresenta, portanto, aspectos similares ao trabalho denominado de reproclutivo.

Nesse sentido. este é um estudo de aborlagem qualitativa e dialética, que tem como objetivo analisar as condições de trabal ho da parteira tradicional, numa perspectiva de trabatho reprodutivo.

\section{TRAJETÓRIA METODOLÓGICA}

Para atingir o objetivo proposio fundamentamos a investigação nas abordagens marxista e feminista. as quais serviram de suporte teórico. A luz clas concepçôes de trabalho produtivo. reprodutivo, gênero e condição feminina, o estudo foi construído. Os pressupostos dos documentos oficiais de saúde e as contribuições de pesquisadores que se dedicaram ao estudo das práticas sociais de saúde também foram facilitaclores cla análise.

O universo empírico para o desenvolvimento dessa pescluisa foi a \%ona rural dos municípios de Rio Branco. Bujari e Porto Acre, representada por ramais, colonias e seringais, terminologias utilizadas para designar localidades rurais.

As localiclades rurais estudadas estão situadas no Esiado do Acre e foram selecionadas considerando-se a facilidade de acesso ao local, a distância e, aincla, ter nessas localidades parteiras que faziam parte do cadastro realizado pela pesquisalora.

Ao todo foram estudadas 11(onze) comunidades rurais e entrevistadas 20 (vinte) parteiras, as quais, estavam situadas em dois grupos:

a) parteiras/agente de saúde:"

b) parteiras. ${ }^{2}$

A coleta procedeu-se no período de março a junho de 1996 e a técnica utilizala foi a entrevista semi estruturada, realizada com apoio de gravações c anotaçoses em cliário de eampo.

\section{AS PESSOAS ESTUDADAS}

As parteiras tradicionais investigadas possuem idades que variam entre 36 a 82 anos. caracterizando-so, portanto, om mulheres de média - avançada idade, prevalecenclo a faixa etária que concentrou-se na escala de 51 a 55 anos. Essa predominância está condizente com a literatura pertinente. conforme 'l'ARGINO (1992). BRASIL (1994) O ORGANIZAÇAO MUNDIAL DE SAÚDE (1992).

O númoro médio de filhos que as parteiras tiveram (09) guarda relação com a experiência de vida dessas mulheres com a parturição, a qual é ouiorgala pela sua auto-observação em parir e pelos partos que roalizam nas lilhas, netas, noras. vizinhas.

A participação de dois homens parteiros nesta pesquisa não altera o perfil sexual das pessoas que realizam o parto no domicílio. caracterizado como

1 Agentes de Saúde contratados pela Secretaria Estadual de Saude - SESACRE, que além de suas atividades, realizan o parto no domicilio rural por solicilaço da própria eomunidade. Nño se trata do agente de Saúdo vineulados ao PACS - Programa de Agentes Comunitários de Saúde.

2 Mulheres ou homens que, por tradição, realizam o parıo no domicílio rural. Popularmente são conhecidas como parteira leiga, curiosa, unadrinha, entre outras denominą̧oes. que variam a depender da culutura local. 
cminentemente feminino. A predominância da mulher auxiliando uma outra no momento do parto, cesta associada a fatores culturais que determinam regras de comportamentos e concepções acerca da moralidade e dos bons costumes. Esses fatores estão enraizados na história da mulher, a qual tem moldado e determinado o perfil feminino e o da ocupação de parteiras. O quantitativo de mulheres na ocupação de parteiras tradicionais esta vinculado, sobretudo. com a própria identidade das parteiras e das mulheres assistidas serem mães.

Como se pode perceber a maioria das parteiras não tinha escolaridade. realidade que condiz com o contexto em que elas vivem, ropresentada por uma qualidade de vida rural subdesenvolvida, onde prectominam precários niveis de educação.

Das parteiras relacionadas, apenas 2 (duas) alirmaram ter realizado treinamentos específicos para parteiras, embora não soubessem informar o ano om que o lizeram nem as instituições que promoveram tais cursos. Elas demonstravam dificuldades para identificar datas, nomes de pessoas, instituięoes e não apresentavam documentos que comprovassem participação nesses troinamentos. Entre as justificativas apontadas para não apresentá-los apareceram: constantes mudanças ro domicílios e tê-los guardado em casa de filhos(as) ou parentes

\section{LOCALIDADES ESTUDADAS}

As Iocalidados visitadas apresentam características semelhantes. relativas as condições de acesso, tipo de transporte. iluminação e infra estrutura sanitária. por sinal, bastante precárias. O acesso é difícil no inverno, sendo ainda mais dificultado por acasião do verão.

A maioria das localidades estudadas não possui iluminação pública, sendo a lluminação garantida por intermédio de lamparinas e cancleeiros. As "porongas", espececie de luminária que funciona a querosene. proporciona a iluminação dos percursos no período noturno. Elas são transportadas fixadas a cabeça das parteiras. promovendo um grande clarão nas matas.

\section{ANÁLISE E DISCUSSÃO}

A analise dos discursos das parteiras confirmou a hipótese levantada na pesquisa, de que o) trabalho de parto realizado no domicílio rural determina. as mulheres parteiras, a realização de outras atividades domésticas dirigidas a parturiente. familiares e ao recém-nascido, caracterizando-se como trabalho reprodutivo. $O$ trabalho da parteira se diferencia do trabalho denominado de produtivo, porque não está associado à criação da mais valia, ao valor de mercadoria, valor de troca pré. determinado. A modalidade de pagamento, como forma de retribuição ao seu trabalho, é estabelecida segundo as possibilidades das mulheres assistidas e, sendo assim, sua prática não implica em pagamento por serviços prestados. Possui caráter humano e social, enfatizado por elementos de natureza afetiva, tais como amor, caridade, bondade, soliclariedade.

A análise foi construída tendo como categoria central o trabalho. Os elementos que perpassam o trabalho da parteira, e que retratam as caracteristicas e as condições em que o mesmo se desenvolve, serviram de suporte para a construção las sub calegorias empíricas: o trabalho da parteira tradicional e assistência ao parto; o trabalho da parteira tradicional e condiçáo feminina; o trabalho da parteira tradicional e reproduçao de relaçoes desiguais; o trabalho da parteira tradicional e legitimidade social; - trabalho da parteira tradicional e praticas terapêtuticas populares na assistência ao parto.

Os resultados obtidos nos permitem afirmar, que na prática obstétrica domiciliar, as parteiras reproduzem o papel feminino, como se pode verilicar no relato abaixo.

"Depois que o menino nasce, corto o umbigo, ajeito a criansa bem ajeitadinha com os panimhos que lem. Se for de noite, faco um caldinho da caridade, que outra coiscr não tem. Quando o dia amanhece, mato a galinha, boto no fogo, pego aquelas roupas sujas do parto e vou lavar. Depois estendo tudo para secar e vou cuidar do almoço da mulher. Faço um pirão escaldado do caldo da galinha e dou para a mulher almosar...na hora de dormir, fico com o bebê. Quando chora, levanto e vou fazer um chá de alfazema. Eu durmo com a crianşa porque a bichinha fica gelada, são poucos paninhos". (P. ent. $\left.N^{\circ} 5\right)$.

Falando dos papéis desempenhados pela mulher na familia e identidade feminina, BRUSCHINI: SAR'IT (1992) alïmam que o próprio processo do socialização encarregou-se de fazer com que as mulhores assumissem as responsabilidades pelos alazeres domesticos como suas. Essa constatação ó reafirmada por FERREIRA (1994). A reforida autora, estudando a mulher e os serviços de saúde em unidades básicas de Salvador - BA, afirma que as proprias mulheres não reconhecem 
as atividades como trabalho, reflexo de uma ideologia que se construiu em torno da mulher. responsabilizando-a pelas tarefas manuais, cuidado com a casa, filhos e marido. Essa questão, a nosso ver, tem favorecido a desvalorização econômica atribuíla pelo Estado e pelas próprias mulheres rurais, ao trabalho desenvolvido pelas parteiras.

Por outro lado, o fato das mulheres assumirem as atividades domésticas como suas está condicionado à fatores culturais que, ainda hoje, concorrem para reter a mulher no lar e para condicionála à situação de reprodutora e responsável pelos filhos.

A pesquisa demonstrou ainda, que o trabalho da parteira reforça a subordinação e submissão feminina, à medida em que se evidenciam, numa mesma ocupação, tarefas diferenciadas entre mulheres e homens, como veremos a seguir.

" Eu não faço esse serviço de casa, eu dou toda a assistência no parto, e ai a parteira que está comigo faz um caldo, di uma massagem, faz um chí, e eu fico lá até a mulher ganhar menino. Depois, o parto fica por conta da parteira. Esse negócio de dar banho em menino, serviço de casa! Isso nõo é coisa pra homem". ( P. ent. $\left.1^{\circ} 09\right)$.

Como observamos, há uma relação desigual entre homens e mulheres, determinando a mulher parteira um estatuto de dependencia e submissão em relação aos homens parteiros.

As atividades domésticas realizadas por ocasião da assistência ao parto, so foram percebidas como atividades realizadas por pessoas do sexo feminino. predominância esta que tem rafzes na historia da mulher, uma historia marcada por episodios que envolvem subordinação, submissão. exploração e discriminação. Sobre essa questão. CARVALHO NETO $(1991$, p.1) assim se posiciona:

"Em verdade, a mulher lem sido secularmente discriminada. Ora presa às tarefas domésticas, nas funções de esposa-mãe, divorciada de 1 mm mundo convertido em espaco dos homens, ora inferiorizada por uma inserşão menos valorizada no mercado de trabalho".

Verificamos, ainda, que as condições cle trabalho das parteiras são determinadas pelos problemas decorrentes das conclições socio-econômicas e culturais, sobreturlo, da deficiência do serviço de saúde local, que não está estruturado para atender a população rural. nem organizado para apoiar o trabalho que as parteiras desenvolvem. Elas realizam o parto no domicílio por uma necessidade social.
A dureza do trabalho, as longas caminhadas, as privações e as dificuldades relatadas pelas parteiras com relaça a falta de material, treinamento, transporte, acesso dificultado e ambiente de trabalho precário representam condições desfavoráveis ao bom desempenho de suas funções; além disso, favorecem a diminuição da capacidade física e psiquica das parteiras. As referidas condições adversas expressam, também, uma con dição de vida margeada por sentimentos de medo, incerteza, insegurança e tensões.

Sentimentos ambivalentes, tais como medo e coragem, alegria e tristeza, sofrimento e prazer, apareceram por diversas vezes nos discursos das entrevistadlas. Através dos sentimentos negativos, demonstraram ter consciência dos riscos de vida a que a mulher e o recém-nascido estão sujeitos, quando um parto se realiza no domicílio rural. Elas têm consciência de que seu conhecimento técnico limitado dificulta a sua atuação, e deste modo, apresentaram expectativas frente a treinamentos.

Os sentimentos positivos, entre eles, alegria e satisfação, estão relacionados com o êxito no trabalho e. desta forma, significam reconhecimento, status e valor social.

Esses sentimentos contraditórios ocorrem em decorrência das precárias condições de trabalho da parteira. Se por um lado seu trabalho gera sentimentos de solidariedade, amor, carinho e bondade, porque oportuniza "a vida", por outro lado, convivem com fenômenos tais como desigualdade social e morte.

Sua prática se configura como uma prática popular, reconhecida e respeitada pela sua comuniclade. Ela se concretiza a través das orações, dọ uso de plantas medicinais, de superstições e de simpatias. Embora essas práticas não sejam de credibiliclacle de todas as parteiras, a fe é incorporada como regra e parâmetro para que o trabalho de parto aconteça sem maiores problemas, independentemente da religião a que pertencem. No trato com as mulheres, apresentam senso de responsabilidade, respeito, necessidade de maiores conhecimentos sobre a assistência ao parto e solidariedade.

\section{CONSIDERAÇÕES FINAIS}

Por não visualizarmos, até o presente momento, comprometimento político com essa camada pobre da população, aqui constituida pelas mulheres rurais, e ainda, por reconhecermos socialmente a importância do trabalho das parteiras no âmbito rural, consideramos a ocupação de partciras tradicionais uma prática social necessária. 
Vale destacar, que embora a gestação se constitua em um estado fisiologico, existem riscos de obito e complicações, aos quais tanto a mãe como o feto estão expostos.

Deste modo, é importante ressaltar que a ausência de serviços de referência, para a parteira encaminhar as gestantes ou parturientes que apresentem riscos, também se constitui em fator de preocupação, já que dificulta a atuação das mulheres que realizam partos nas zonas rurais, bem como, coloca em risco a vida das parturientes que têm o parto distante dos serviços especializados.

Este fato caracteriza a omissão do Estado na prestação da assistência materna rural e, ainda, a falha do sistema de saúde, já que o direito à saúde é garantido constitucionalmente.

Estamos conscientes de que o conhecimento da situação configurada não necessariamente gera comprometimentos, e que estes dependem de vontade e decisão política dos gestores dos serviços de saúdle e da população feminina, para modificar a realidade existente.

\section{REFERÊNCIAS BIBLIOGRÁFICAS}

BRASIL. Ministério da Saúde. Secretaria de Assisténcia à Saúde. Departamento de Promoçáo e Assistencia à Saúde. Coordenaça Materuo Infantil. Diretrizes básicas de assistencia no parto domiciliar por parteiras tradicionais: Programa de Assistencia Integral à Saúde da Mulher. Brasilia, 1994.

BRUSCHINI. C.; SARTI, C. I Transa legal. Sao Paulo, ECUS, 1992. (Texto de apoio).

CARVALHO NETO. J.F.de. A condição da mulher policial civil: un estudo sobre a mulher inserida no aparelho policial 1991. 105 p. Dissertaço (Mestrado). Faculdade de Filosofia e Ciencias Hunanas, Universidade Federal da Bahia.

FERREIRA. S.L. A mulher e os servigos públicos de saúde análise do processos de trabalho em unidades básicas de Salvador-BA. Ribeir ao Preto 1994. 207 p. Tese (Doutorado). Escola de Enfermagem de Ribeirăo Preto, Universidade de Săo Paulo.

ORGANIZACAO MUNDIAL DE SAÚDE. Parteiras leigas: uma declaraç̃o conjunta. OMS/FNNAP/UNICEF. Genebra, 1992.

TARGINO, R.B. Visão sócio-antropológica da parteira curiosa: dimensoes política-educativa-terapeutica: rezas, ritos, ervas. Rio de Janeiro, Cultura Médica, 1992 